\title{
THE IMPROVEMENT OF THE INVENTORY PROCESS IN THE COMPANY "BENLIAN FOOD" NIŠ BY APPLYING THE POM-QM 4.0 SOFTWARE
}

\author{
Milan Stojanović, \\ Dušan Regodić
}

Singidunum University, 32 Danijelova Street, Belgrade, Serbia
Correspondence:

Milan Stojanović

e-mail:

milanstojanovic19@yahoo.com

\begin{abstract}
:
One of the most important factors of an enterprise's efficiency is also adjusting of supply with demand requirements. Logistics, as an integral function of an enterprise that establishes and develops relations with the environment and, in a targeted manner, directs the subsystems of a company towards the main goal of its existence and operation, is the most appropriate tool for managing an enterprise in the modern dynamic environment.

In many enterprises, inventory optimization is a major problem. Mainly, such enterprises are characterized by poor customer service, such as failure to adhere to delivery deadlines. Bearing in mind the state of Serbian companies, few enterprises can boast their applied scientific knowledge in the field of inventory optimization in practice.
\end{abstract}

The subject of our research is the optimization of the inventory in the company Benlian Food Niš. The management of the company finds it rather significant to know approximately exact quantities needed for the next year. Given the fact that this is an importing company with its production, too, more precise quantities would be of great help, as this would enable management to make more adequate decisions on when and how many products to import and produce.

Key words:

inventory management, optimization, supply chains, forecasting, POM-QM software for Windows 4.0.

\section{INTRODUCTION}

Forecasting is one of the most important inputs managers develop as a support to the decision-making process. In that sense, managers find the question of whether greater significance should be attributed to quantitative methods of forecasting or to one's own opinion and one's own estimations to be one of the key questions. Experience shows that a combination of quantitative methods and a good estimation, founded on sound logic, is a recipe for good forecasting. Also, the question imposes as to whether there are ways for our cognitive capacities and our estimations founded on them to anticipate unexpected changes in the business environment, which would create conditions for a timely and efficient evaluation of alternative courses of action?

In many enterprises, inventory optimization stands for a major problem. Mainly, such enterprises are characterized by poor customer service, such as a failure to adhere to delivery deadlines. Having in view the condition of Serbian enterprises, few enterprises can boast their applied scientific knowledge in the field of inventory optimization in practice. 
The subject of our research is the optimization of inventory in the company Benlian Food Niš. The management of the company finds it rather significant to know approximately exact quantities needed for the next year. Although it is a very successful enterprise, the prediction process is based on the reasoning and opining of the management of the enterprise. Given the fact that this is an importing company with its production, too, more precise quantities would be of great help, because in such a way, management would be making more adequate decisions on when and how many products to import and produce.

For that very reason, the basic goal of the paper is point at the advantages and benefits which the enterprise can achieve by applying a conventional approach to prediction, mainly focused on the development and testing of statistical techniques. In that sense, software packages developed as a support to the multiple criteria analysis models are also a significant segment.

\section{THE CHOICE OF INVENTORY OPTIMIZATION SOFTWARE}

The contemporary conditions of business doing have imposed upon enterprises basing their business doing on an adequate information support. Without adequate information solutions, there is no cost-effective or profitable business doing of enterprises in the turbulent environment, either. The advancement of technology has had such an impact leading to the emergence of different types of information systems for different fields of business doing inside an enterprise.

The movement of goods must be supported by an information system. When right goods move towards the right place and at the right time and in right conditions, with right documents, right information, i.e. answers to all "right" questions must be known (Regodić, 2010, p. 359).

Given the fact that the business doing of an enterprise includes many activities, there are general information systems and specialized IT solutions. When supply, the logistics of inventory and shipment are concerned, information technologies may accelerate the processes, reduce costs and thus be the enterprise's success factor. "Software must be in function of joint work on the rationalization of the production-business processes, but also must be rational by itself: with a few input data and capable of generating purposeful management information." (Stanišić \& Regodić, 2009, p. 93).

Planning not supported by computers is impossible in contemporary enterprises. However, integral computer tools are mainly expensive (sometimes, they may even cost several tens of thousands of euros). Apart from this, program solutions require more powerful hardware and software as well as a database system in the process of the implementation of a program solution in an enterprise.

A problem may occur in smaller enterprises unable to afford expensive software solutions, so the quality of their planning is also frequently questionable. Minor program solutions supportive of the complex calculations of planning are helpful in planning and are also an interesting tool. At the same time, they are very powerful computer tools not specially demanding in terms of the computer performances and big capacities of the memory.

Logistics information systems are impossible to do research into, develop and introduce in operating practice (apply) unless there is knowledge of the important features of quality information systems. Quality information systems supporting the logistic aspects of decision making and supporting the work done by the logistics bodies cannot be developed unless the information needs of certain users of information systems (information) are adequately defined and unless the objects of the interest of a logistics system are described in as many details as possible (Andrejić, Milenkov, Sokolović, 2010, p. 34).

In the context of inventory optimization, we shall use the POM-QM solution for Windows in this paper. For the time being, 4.0 is the latest version of this program solution. It should also be emphasized that there are similar software solutions in the market, as well as a large number of different types. Some are available free of charge on the Internet, and some are possible to obtain for just a few euros.

The first version of this software was a DOS version that appeared in 1989, as the PC-POM. The following DOS versions were named AB:POM. The first Windows version, the QM for Windows (Version 1.0) was distributed in the autumn of 1996, as a special but similar program. The POM for Windows (Version 1.1) was distributed in the autumn of 1996 for the first time. The DS for Windows version included the POM and the QM modules and, together with the instructions for use, it was distributed in 1997. The Version 2 of all the three programs was created for Windows 95 and appeared in the autumn of 1999. (Weiss, 2010, p. vii). The upgraded version of the POM-QM for Windows 4.0 came to fruition during 2010, and it is possible to download it free of charge on the Internet. ${ }^{1}$

1 For more information about this: http://pom-qm-forwindows-version-4.software.informer.com/ ( $4^{\text {th }}$ March 2016) 
The POM-QM 4.0 software solution consists of more than twenty different modules, and it is possible to have some of them additionally structured as well. Given the fact that there is a large number of complex modules, only those that will be used in the paper will be presented in more detail. This refers to the Inventory and the Forecasting modules.

Principally, work with different modules in a software solution is quite similar. The very beginning is based on entering data, only to be followed by solving and finally interpreting data. Each of the modules enables the entering of new data (File, New) or work with the existing or saved data (File, Open). The POM-QM 4.0 software solution has the following modules: the production program planning, the production line reconciliation, mapping work on machines, the break-even point analysis/cost analysis, capital investment, help when making decisions, forecasting, the theory of games, goals programing, integrated programing, inventories (storing), term planning, allocation, the experience curve, linear programing, the allocation of production resources, the optimization of the order quantity, the Markov analysis, the planning of material needs, networking (the optimization of the route), productivity, project management (PERT/CPM), quality control, reliability, simulation, statistics (average, variation, standard deviation, normal distribution), shipment problem, waiting queues, and results measuring.

Once a module of forecasting is determined, it is possible to present four submodules through the main menu (File, New): Time Series Analysis, Least Squares/ Simple and Multiple Regression, Regression Projector, and Error Analysis.

When data have been entered, by pressing the button (Solve), the required calculation is initiated. The results are displayed in several windows, depending on the selected calculation module: BAS (Mean Error), MAD (Mean Squared Error), Standard Error, MAPE (Mean Absolute Percent Error).

When the Inventory module has been selected, as it is the case with the module Forecasting on Command (File, New), we are faced with the possibilities of selecting different submodules: the Economic Order Quantity (EOQ) Model, the Production Order Quantity Model, the Backorder Inventory Model, the Production with Backorders Model, Quantity Discount (EOQ) Model, ABC Analysis, Record Point/Safety Stock (Normal Distribution), Record Point/Safety Stock (Discrete Distribution).

After data have been entered, by pressing the Solve button, the calculation itself is initiated. The results can be displayed in several windows, which depends on the selection of the module. The coverage of the solution depends on the complexity of the problem observed. The results in this module are mainly displayed in two windows.

In the first window, the results obtained on the basis of the EOQ selected model are displayed: input data (annual needs, costs of ordering, costs of storing and the price), the optimal order quantity, the maximum inventory level, (average inventory), annual setup costs, annual holding costs, unit costs, total costs.

As it could have been seen in the shorter presentation of the POM-QM software solution for Windows 4.0, the software is easy to use. Of course, it is necessary that there should be the knowledge of the formulation of the problem and the purpose of solving the same. It should also be pointed out that the POM-QM software solution for Windows 4.0 is an attractive tool.

Apart from being attractive and easy to use, too, however, it can also be said to have some shortcomings. We are going to try to list them:

- The capacity of some of the modules is rather restricted (almost all the modules allow using a table of no more than 90 data or tables of up to 90 rows and columns);

- The software solution lacks a database, so each time, data need to be entered "manually";

- The results of the solution to the problem in the software solution are not visible in the best possible manner when exported, so, in the majority of cases, it is necessary that their visibility should be improved through other programs;

- Networking and the exchange of information with other tools is not possible, except with Excel, so, in accordance with that, it is impossible to apply in computer networks;

- The program solution is in the English language.

- Yet, perceiving all the mentioned shortcomings, it is possible to conclude that the POM-QM software solution for Windows 4.0 is quite a satisfactory tool that can be used in solving problems in the field of quantitative methods (QM) and production and operations management (POM). The software solution is also fully free of charge and very simple to use, which enables its quick and easy implementation in the enterprise.

Based on the said so far, the key reasons that have contributed to the selection of the software are: (1) the functionalities are sufficient for the application of simple inventory models as is the one applied in the paper; (2) 
the software is relatively easy to use; (3) the software is cost-effective because it is free to use.

\section{THE RESULTS AND DISCUSSION}

The company Benlian Food doo (limited liability company) was founded by Raffi Benlian in Niš in June 2001, when its main activity was the import and distribution of, first of all, granular, basic provisions. The company is part of an international group doing business on the territory of Central Europe and the Balkans, and in that way, it keeps up with the world trends, which they are trying to bring onto the Serbian market in the best possible way.

The company has quite a wide portfolio. The main activity is the import and packing of rice. Apart from that, there is also a confectionary sector, as well as the sector of pasteurized food, ketchup, dried leguminous vegetables and cereals. Kozmetik plus doo is also within the company. Kozmetik plus is part of the group for the import, processing and distribution of rice for the SouthEast European market. (http://www.vibilia.rs/srpski/ izvestaj/0508/Benlian.pdf, $5^{\text {th }}$ March 2016)

At the beginning of business doing, in January 2002, the company Benlian Food employed five workers. Given the fact that the company is still developing itself, it currently employs more than 250 workers, showing a tendency of increasing the number of its employees. Its annual turnover is higher than 8,000,000 EUR, and the profit of around 2\% (http://www.kozmetikplus.com/ onama.swf, $5^{\text {th }}$ March 2016)

The company offers over 50 articles and they all belong to the food category, but there are also confectionary products. That is exactly the reason why potential buyers of products are different. The Benlian Food Company's products are present on the territory of Serbia as well as outside that territory. It can be said to be an enterprise focused on the production of products generating the highest profit. Yet, rice is one of the products for which the company Benlian Food Niš is recognizable on the market.

Although it is a very successful enterprise, the enterprise does not base its business operations on the optimization of inventories by applying statistical techniques or some software package. The applied concept of the intuitive planning of the sale of goods has had an impact on an increase in the costs of business operations due to the lacking inventories or the existence of a surplus of inventories.

The inadequate sales plan leads to the problem of inventories in the enterprise. Inventories happen to be either too small or too large, and in both cases, they con- tribute to an increase in costs. The additional burdening factor is that production depends on import. So, to the extent it is feasible, a detailed sales plan would be significantly helpful in the business operations carried out by the Benlian Food enterprise. In such a manner, the enterprise would be striving for an adequate optimization of its inventories.

In the continuation of the paper, we shall present the example of increasing costs caused by a bad sales plan. The example is based on the data for the year 2015. We have chosen the three different sorts of rice that were being sold the most. The following graph accounts for the sale of the three chosen sorts of rice in 2015.

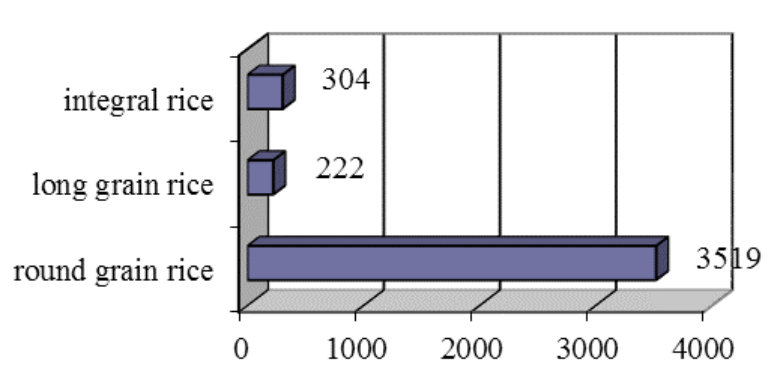

Graph 1: The sale of the three sorts of rice during 2015, expressed in tons. Source: The company Benlian Food

Ltd. Niš, inside documentation

On the basis of Graph 1, we can clearly perceive that the sales quantities of the three sorts of rice differ from each other. We should bear in mind the fact that it is the sale achieved in the course of 2015, not the predicted sale on the base of which the enterprise can take measures so as to avoid the consequences of a lack of inventories or redundant ones. However, in 2015, that was exactly the problem. We shall graphically account for the surplus/ deficit with respect to all the three sorts of rice.

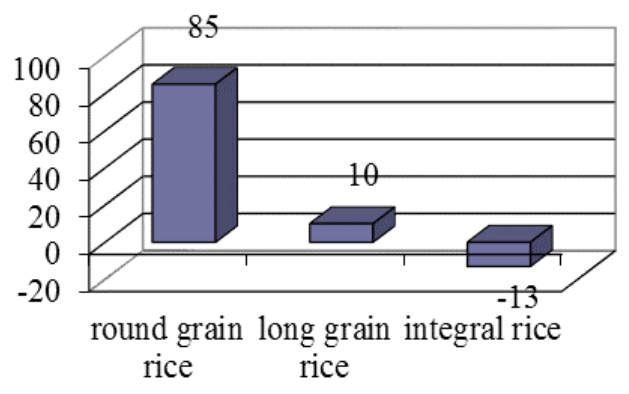

Graph 2. The inventories surplus/deficit in 2015, expressed in tons.

Source: The company Benlian Food Ltd. Niš, inside documentation 
On the basis of the presented graph, we can clearly see that, in 2015, there was a surplus of inventories for round grain rice $(85 \mathrm{t})$ and long grain rice $(10 \mathrm{t})$, and when integral rice is concerned, there was a shortage of inventories (13t). No matter which one of these situations - the surplus or the shortage of inventories - is considered, they both contribute to increasing the costs of business operations.

The prices of individual products, excluding the sales margin, were as follows in 2015 (The company Benlian Food Ltd. Niš, inside documentation):

- round grain rice $=55.00 \mathrm{din} / \mathrm{kg}$,

- long grain rice $=38.50 \mathrm{din} / \mathrm{kg}$,

- integral rice $=56.50 \mathrm{din} / \mathrm{kg}$.

On the basis of the presented data, we shall indicate the level of unnecessary costs in the Benlian Food Niš enterprise. We may also examine the total amount of costs, taking into consideration all the inventories of the enterprise's assortment.

For the presented products, the value of the surplus/ deficit of the inventories is obtained by multiplying the price by the quantity of the surplus/deficit of the inventories (respectively).
- round grain rice $=55.00 \mathrm{RSD} * 85,000 \mathrm{~kg}=$ 4,675,000.00 RSD/godišnje,

- long grain rice $=38.50 \mathrm{RSD} * 10,000 \mathrm{~kg}=$ 385,000.00 RSD/per annum, and

- integral rice $=56.50 \mathrm{RSD} * 13,000 \mathrm{~kg}=734,500$ RSD/per annum.

On the basis of the presented, the total costs of the surplus/deficit of the inventories of the observed products amount to 5,794,500.00 RSD/per annum.

As we have already mentioned, having in view the complete assortment of the Benlian Food Niš enterprise, the total annual costs of the surplus/deficit of the inventories are for sure far greater.

For that particular reason, we propose inventory optimization in the Benlian Food enterprise by applying the POM-QM software solution for Windows 4.0., which in turn will lead to far more realistic sales plans as well, which will ultimately result in a reduction in the costs of business operations, too.

The table below is an account of the data on the sale of round grain rice for the last two years, per months, i.e. in the period 2014-2015. In accordance with the period of the observation of the sales trend, the forecasting (forecast) will refer to the year 2016.

\begin{tabular}{lcccccccccccc}
\hline & Jan. & Feb. & March & April & May & June & July & Aug. & Sept. & Oct. & Nov. & Dec. \\
\hline $\mathbf{2 0 1 4}$ & 261 & 289 & 316 & 298 & 280 & 264 & 299 & 282 & 289 & 306 & 261 & 288 \\
\hline $\mathbf{2 0 1 5}$ & 316 & 335 & 367 & 328 & 299 & 336 & 358 & 345 & 314 & 307 & 354 & 386 \\
\hline
\end{tabular}

Table 1. The data on the sale of round grain rice in the period 2014-2015, in tons.

Source: The company Benlian Food Ltd. Niš, inside documentation

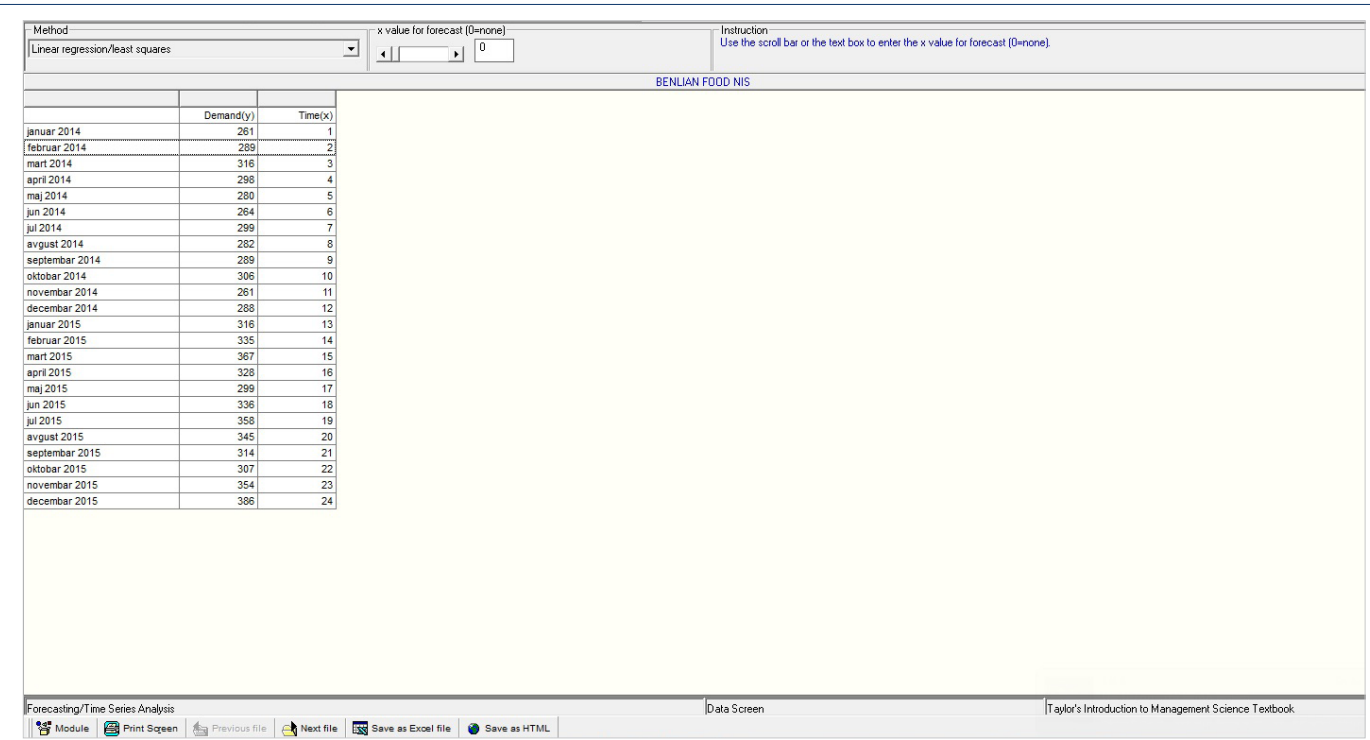

Picture 1. The input data for the selected product in the POM-QM software for Windows 4.0. 
The process of forecasting by applying the POM-QM software solution for Windows 4.0 instructs us to enter the requested data into the program, so as to calculate all the parameters necessary for linear regression.

The data on the sale of round grain rice for the two years are entered in the main window for entering data. After the data have been entered, whether the entered data are accurate should be checked, after which by pressing the Solve button, the results necessary for solving the set problem are obtained very quickly and easily. Apart from that, the program also enables a graphical display of the results.

The results obtained by means of the correlation method of the regression analysis according to the least squares method, on the basis of the calculation done by the POM-QM software for Windows 4.0, are as follows:

- Bias (Mean Error) $=0$

- $\operatorname{MAD}($ Mean Absolute Deviation) $=18.84$

- MSE (Mean Squared Error) = 536.04

- Regression line $=$ has the $Y$ shape $=a+b^{*} x=$ $268.51+3.45^{\star}$ month $(\mathrm{x})$

- Correlation coefficient $=0.72$

- Coefficient of determination $\left(\mathrm{r}^{2}\right)=0.51$.

The graphical display of the forecasting of the sale of the round grain rice of the company Benlian Food Niš is presented in the following picture.

By summarizing the obtained results of the forecasting, the following can be highlighted:
- the total sale of round grain rice in 2014 was $3,433 t$

- the total sale of round grain rice in 2015 was 4,045 ;

- according to the forecasting for 2016, the sale will be greater than in 2014 and 2015, and will amount to $4,484.4 \mathrm{t}$.

Inventory optimization on the basis of the forecasting is continued by using the Optimal Order Quantity model (the EKN model). The core purpose of the Optimal Order Quantity Model in an enterprise is how to lower the costs incurred due to a lack or a surplus of inventories.

The input data for the Optimal Order Quantity model for round grain rice (the observed product) are as follows:

$\mathrm{P}=4,484.4 \mathrm{t}$ - the obtained forecasting for 2016 ,

the purchase price: $\mathrm{N}_{\mathrm{c}}=59.00 \mathrm{din} / \mathrm{kg}$, i.e. $59,000 \mathrm{din} / \mathrm{t}$ the costs of ordering a single delivery: $T_{n}=146,000$ RSD

the costs of storing: $\mathrm{s}_{\mathrm{z}}=59,000^{\star} 0.12=7,080.00 \mathrm{din} / \mathrm{t}$

The POM-QM program solution for Windows 4.0. determined 18.84 - the monthly level - for the mean average deviation (MAD). On the basis of that, we can define the lower and the upper limits of the event, namely:

the lower limit of the event: $4,484.4-2.5^{\star} 12^{\star} 18.84=$ $4,484.4-565.2=3,919.2 \mathrm{t}$

the upper limit of the event: $4,484.4+2.5^{\star} 12^{\star} 18.84=$ $4,484.4+565.2=5,049.6 \mathrm{t}$

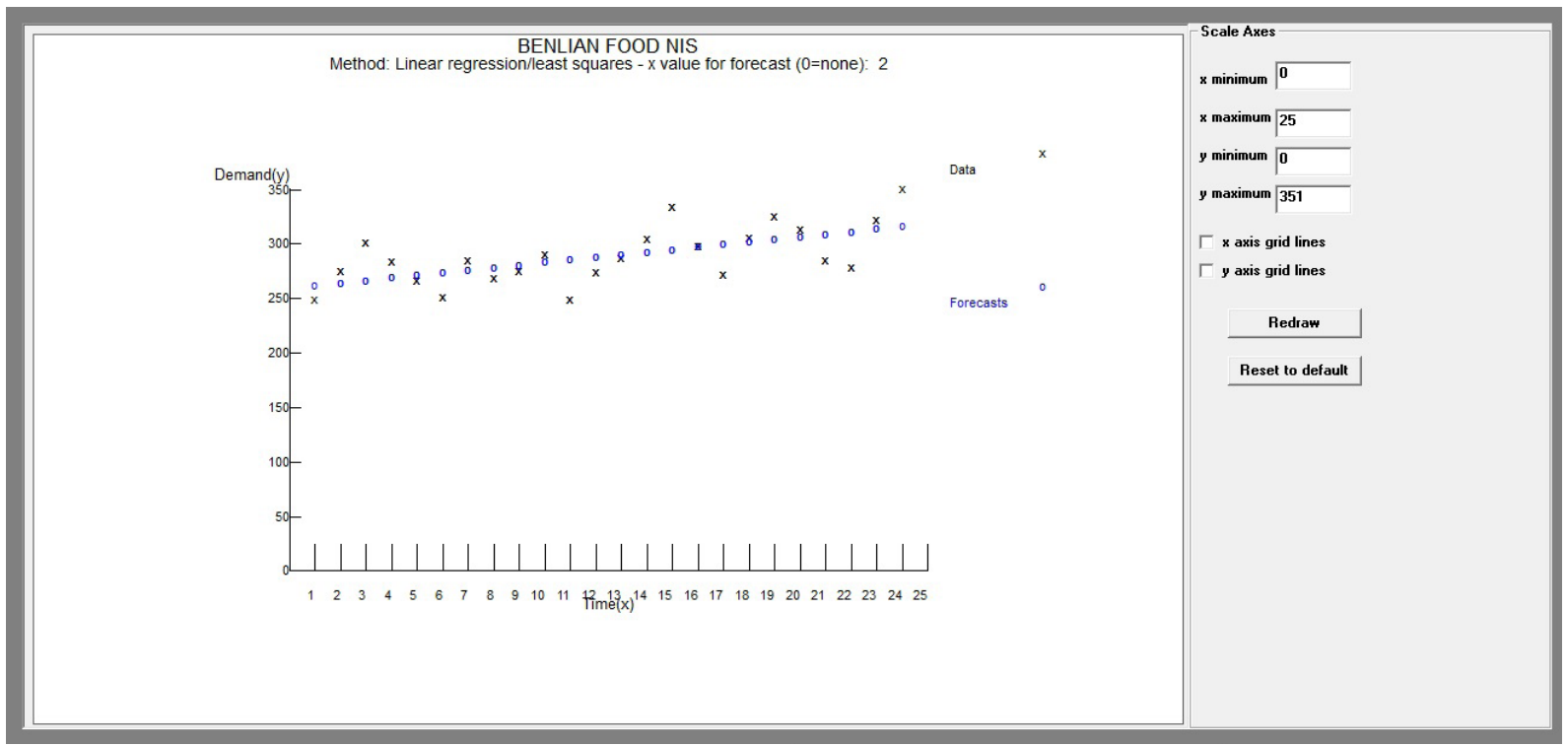

Picture 2. A display of the forecasting of the sale of round grain rice on the basis of the POM-QM software for Windows 4.0. 
By entering the data in the POM-QM program solution for Windows 4.0., the results are obtained so that, on the basis of the four scenarios, namely:

1. a normal distribution at the level of $95 \%$ of the supply level - the lower limit $-2 \sigma\left(-2.5^{\star} \mathrm{MAD}\right)$,

2. a normal distribution at the level of $95 \%$ of the supply level - the upper limit $+2 \sigma\left(+2.5^{\star} \mathrm{MAD}\right)$,

3. a normal distribution at the level of $95 \%$ of the supply level - the upper limit $+/-2 \sigma\left(+/-2.5^{*} \mathrm{MAD}\right)$,

4. intuitive ordering,

we could make a decision on the scenario with the most optimal solution for the company Benlian Food Niš.

The optimal order quantities and the number of purchases according to the different scenarios are accounted for in the following table.

\begin{tabular}{cc}
\hline Optimal Order Quantity: & Number of orders: \\
\hline $1^{\text {st }}$ scenario: $402.4 \mathrm{t}$ & 10 times \\
\hline $2^{\text {nd }}$ scenario: $456.34 \mathrm{t}$ & 11 times \\
\hline $3^{\text {rd }}$ scenario: $430.06 \mathrm{t}$ & 10.43 times \\
\hline $4^{\text {th }}$ scenario: $2,328.5 \mathrm{t}$ & 2 times \\
\hline
\end{tabular}

Table 2. The optimal order quantities and the number of the purchases according to the different scenarios.

After comparing the optimal order quantity and the number of orders, it is also significant to make a comparison between the total costs and the annual quantities of all the four scenarios. For that very reason, the same is going to be shown graphically.

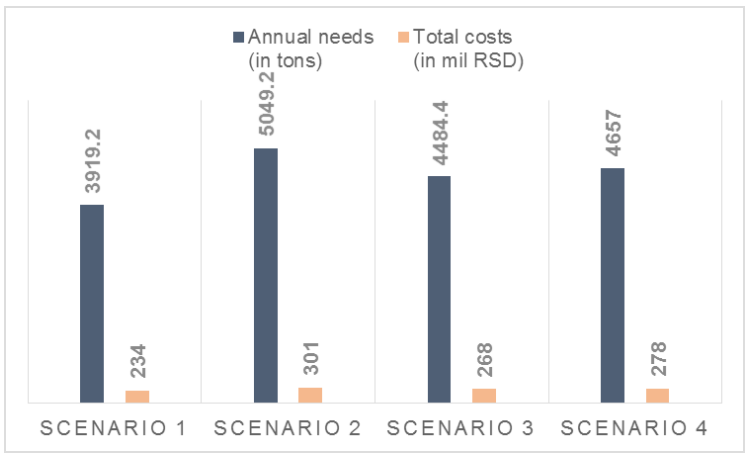

Graph 1. A comparative display of the total annual costs and quantities of different scenarios.
The presented data are clearly indicative of the fact that Scenario 1 is the most acceptable scenario for the Benlian Food enterprise with respect to the costs. Scenario 1 envisages costs in the amount of 239 million RSD, whereas the other scenarios envisage greater costs, namely:

- Scenario 2 envisages costs greater by 63 million RSD which is about $26 \%$ greater than the costs according to Scenario 1 ,

- Scenario 3 accounts for costs greater by 30 million RSD, i.e. about $13 \%$ in excess of the costs according to Scenario 1 ,

- Scenario 4 envisages costs greater by 40 million RSD, i.e. about $17 \%$ greater than the costs according to Scenario 1.

By applying Scenario 1 when placing an order for round grain rice, the costs of business operations would surely be lower than they were in the previous period because the costs of the surplus/deficit of the inventories would be reduced to the minimum. As we could see, due to the surplus/deficit of the round grain rice inventories in 2015, the costs amounted to around 5.8 million RSD. Having in view the large number of the products in the assortment of this enterprise, the application of the proposed optimization has its economic justification. The economic effects of the application of Scenario 1 in the business operations conducted by the enterprise would be measurable only in the next year, when there is a clear insight into the costs of the surplus/deficit of the inventories.

However, we should bear in mind the fact that there is no written rule telling us when an enterprise should be applying some of the scenarios. The permanent monitoring of the level of inventories and sales flows imposes itself as a necessity so as to prevent too high a level of inventories or a shortage of the same.

The idea of optimization, on the example of the company Benlian Food Nišs, also indicates the fact that it is impossible to calculate all on the basis of various methods, but that it is necessary that the opinions of the company's management should also be included in making decisions on inventory optimization. Even when statistical methods are used, it is not a rare case that results are adjusted according to experts' assessments. Managers usually have access to a broad spectrum of information they have to integrate so as to make a forecast.

\section{CONCLUSION}

The proposed inventory optimization brings results in many segments, but the key effects are reflected in inventory optimization in the sales plans of the company 
Benlian Food Niš, and accordingly, in the reduction of the costs. In practice, that would mean that, due to the implementation of one such system, the enterprise would in a simpler manner draft its purchase plan that would deviate less from the intuitive forecasting of the management of the enterprise. Simultaneously, a more advanced inventory management system would be established. Yet, the most significant segment would be the one in the domain of avoiding unneeded costs increased due to inaccurate sales plans and lacking/excessive inventories.

As the basic preconditions for the implementation of one such inventory optimization in an enterprise, the following ones can be mentioned: employees must be ready to permanently educate themselves, because the basic knowledge of the planning methods and techniques, as well as in the field of logistics are necessary; the intuitive application of methods is necessary in order to obtain appropriate results; it is necessary that they should have knowledge of working in a software program for operations management and quantitative methods, such as the used program POM-QM for Windows 4.0. (or a similar program solution) for the purpose of supporting the planning process.

We also need to mention that time is an important factor for the implementation of the mentioned solution. It is not realistic to expect that the whole of the process can be ended in a short time period, since the process as a whole requires a certain period of time, in the context of which we should bear in mind the fact that the most time will be dedicated to educating employees.

Apart from that, it is rather important that there should be an essential support provided by the management for the whole of the process. The experiences gained with the employees at the Benlian Food Niš enterprise are very positive ones and they were really very friendly. However, business secret, mainly adhered to by enterprises when their business documentation is concerned, appears to be one of the limiting factors for writing papers of this kind is. When we speak about enterprises which deal with the sale and implementation of program solutions and have to keep business secret in accordance with the executed agreement of business cooperation, then the approach quite differs.
One of the advantages of the proposed optimization is the costs of introduction. The costs of the implementation of the proposed solution are negligible, so that it is impossible to speak about an increase in financial costs. Thus, the used software solution is free of charge, and if it should be bought, no significant funds are required. Ultimately, to have knowledge of the Excel software program in the field of planning is sufficient.

In the end, it should be said that the proposed solution would be very beneficial for the Benlian Food Niš enterprise, as well as for many other enterprises. Given the fact that the management and employees of the majority of Serbian enterprises forecast their sales plans on the basis of their own discretion (feeling) rather than on the basis of some concrete methods or program solutions, simultaneously their forecasts are of a poorer quality. Upon the successful introduction of the proposed solution, there is one thing for sure - there would be an increase in the accuracy (quality) of sales plans.

\section{REFERENCES}

Andrejić M., Milenkov M., \& Sokolović V. (2010). Logistički informacioni sistem. Vojnotehnički glasnik, 10(1), 33-61.

Benlian Food. (2016). O nama. Retrieved 05.03.2016 from http://www.kozmetikplus.com/onama.swf.

Informer Technologies, Inc. (2016). POM-QM for Windows (Version 4). Retrieved 04.03.2016 from http:// pom-qm-for-windows-version-4.software.informer.com/.

Preduzeće „Benlian Food” doo Niš, Interna dokumentacija.

Progressive. (2016). Intervju: Raffi Benlian, direktor Kozmetik Plus NOVI NAČIN UŽIVANJA U HRANI. Retrieved 05.03.2016 from http://www.vibilia. rs/srpski/izvestaj/0508/Benlian.pdf.

Regodić, D. (2010). Logistika, Beograd: Univerzitet Singidunum.

Stanišić, M., \& Regodić, D. (2009). Informacioni sistem integrisane logistike i podrška nabavkama. 1. Naučni skup sa međunarodnim učešćem Sinergija 2009 (pp 87-93). Bijeljina: Univerzitet Sinergija. 